\title{
A memória através dos livros: o livro na biblioteca e a biblioteca na escola
}

\section{The memory through books: the book in the library and the library in the school}

https://doi.org/10.34112/2317-0972a2019v37n76p13-26

\section{André Luiz Paulilo ${ }^{1}$}

RESUMO: O texto tem como proposta principal apresentar algumas questões relacionadas à importância da biblioteca escolar para a consolidação das práticas de leitura. $\mathrm{O}$ ensaio, primeiramente, adianta alguns pressupostos de pesquisa e apresenta uma reflexão a partir das ideias de Gerard Namer sobre a relação entre biblioteca e memória social. Em seguida, discute as afirmações de Fernando de Azevedo e Maria Reis Campos acerca do papel do livro para a atividade docente. Na conclusão, destaca a relevância da história do ensino da leitura na biblioteca para o estudo das práticas escolares e para a historiografia da educação. PALAVRAS-ChAVE: Biblioteca escolar; memória; livro; cultura material escolar.

ABSTRACT: The text has as main proposal to present some questions related with the library importance to reading practices consolidation. Firstly, this essay antecipates some research assumptions and presents a reflection from the ideas of Gerard Namer about relation between library and social memory. Secondly, it discusses the statements of Fernando de Azevedo and Maria Reis Campos about the role of the book for the teaching activity. In conclusion, it highlights the theme relevance to studies about school practices and to historiography of education.

KEYWORDS: School library; memory; book; school material culture.

1. Universidade Estadual de Campinas, Campinas, SP, Brasil. 
Centrais na rediscussão da história cultural, o livro e as práticas de leitura são domínios da pesquisa em que melhor se mapeou os circuitos de produção, difusão e apropriação cultural. Conforme mostrou Darnton (1990, p. 110-111), no curto período de vinte anos a história dos livros se tornou um campo de estudos rico e diversificado. Nesse sentido, desde a experiência literária de leitores comuns até as instituições que se organizaram em torno do livro e da cultura escrita, esses estudos vêm mostrando a importância de renovar as questões, experimentar novos métodos e ampliar as fontes de pesquisa das relações entre a cultura, a sociedade e a economia.

Entre o muito já realizado nesse domínio específico de pesquisa, há alguns caminhos que, embora abertos, ainda são pouco frequentados. O propósito deste texto é percorrer um desses caminhos. Desejou-se explorar aqui a intersecção já sugerida por Namer (1987) entre os livros, a biblioteca e a memória. Sua análise da biblioteca como instituição de memória do saber e da cultura sugere aproximar o livro das práticas de sua catalogação e teve pouca continuidade. Aqui, a discussão que Namer faz do acesso à memória livresca por meio das operações de sentido produzidas na elaboração do catálogo de uma biblioteca foi o mote para a pergunta sobre o tipo de circuito de produção que liga a escola aos processos de produção, difusão e apropriação de uma memória cultural.

Não se tratou aqui de pensar as possibilidades de um modelo explicativo. Ao contrário, apenas se quis sugerir que, na relação entre o trabalho intelectual e a hierarquia de práticas que se organiza em torno do livro numa biblioteca, a escola foi um fator relevante. O propósito, então, foi discutir as questões propostas por Namer (1987) a partir do estudo da biblioteca escolar. Antes disso, contudo, procurou-se adiantar a discussão de alguns dos pressupostos da pesquisa e, desse modo, explorar do ponto de vista da história cultural algumas das relações possíveis entre o livro, a cultura material escolar e a memória.

\section{O LiVRo NA BIbLIOTECA, DOS SEUS SENTIDOS E SIGNIFICADOS}

Segundo a compreensão de Gerard Namer (1987), as bibliotecas organizam uma prática particular de memória cultural, que é a leitura. A partir de Halbwachs, desenvolve-se a ideia de que a massa de livros reunida numa biblioteca contém uma memória do mundo. Para Namer (1987, p. 160) “tout se passe comme si la masse des livres disponibles était une mémoire virtuelle qui s'actualiserait par la lecture dans la salle de travail”. Sobretudo, ele entende que a biblioteca é instrumento permanente 
de uma sociedade cuja memória cultural, mas igualmente política ou administrativa, impõe aos leitores vir a demandar livros.

O acúmulo de livros numa biblioteca resulta, conforme entende Namer, de diferentes formas de unificar lembranças para o uso e avaliação de autênticas comunidades de leitores. Os livros são reunidos numa biblioteca como uma memória social, acessível à demanda de práticos da memória como o são os eruditos, professores e também os bibliotecários. Trata-se de um fenômeno de todos os tempos. Assim, o mesmo Namer explica que em diferentes épocas as coleções de livros formam um conjunto coerente com um jogo de citações e comentários (1987, p. 162). Prefácios, dicionários de citações, teses, manuais de referência são entendidos como dispositivos de memória cultural livresca que permitem duas formas opostas de apropriação. De um lado, a repetição de um modelo de autoridade cultural por conta do seu significado ou da sua forma. De outro, a renovação do modelo por uma reconstrução análoga, depois de um trabalho de desconstrução.

Por esse jogo se formou durante séculos o essencial da memória cultural religiosa. As bibliotecas dos príncipes serviram, de outro modo, mas segundo o mesmo jogo, de meio para legitimar a memória oral e a tradição de uma política. Segundo o mesmo tipo de análise, se as bibliotecas dos príncipes acumularam o saber esotérico do poder, às bibliotecas públicas, ao contrário, destinou-se a lembrança da afetividade de uma sociedade. Nesse caso, elas não são apenas uma acumulação de saber estético, proveniente da literatura, mas um espaço de preservação da memória cultural de que fala Namer (1987).

No Brasil, depois de 1808, a criação da Biblioteca Nacional, do Real Gabinete Português de Leitura, da Faculdade de Medicina e de toda uma série de instituições culturais fez multiplicar os espaços de acumulação de acervos bibliográficos. E boa parte do trabalho de construção da memória nacional se beneficiou desses espaços do saber. Já em fins do oitocentos, a produção do Instituto Histórico e Geográfico Brasileiro (IHGB), por exemplo, foi constituída através desses espaços. A pesquisa documental que sustentava a produção do IHGB foi, em grande parte, praticada em bibliotecas. Além disso, a construção das narrativas históricas sobre o passado da nação e a mobilização de estratégias para sua divulgação abarcavam inúmeras disputas, que, devido ao fortalecimento do poder do livro como depositário privilegiado do saber escolar, transformavam a organização de bibliotecas num ato de vontade e interesse político. Dessa perspectiva, a própria escolarização mobilizava os saberes legitimados nesses mesmos espaços, contribuindo para a circulação de 
uma determinada memória nacional. Os estudos a respeito do ensino de história, sobretudo, mostram bem o papel dos livros nesse processo. Segundo sugere Circe Bittencourt (2008, p.162), os manuais didáticos de História foram peças fundamentais na produção e transmissão da identidade nacional.

Há razões para crer que esse esquema da difusão da memória nacional não seja o único do qual a escola participava. A recente historiografia da educação já reúne um número significativo de exemplos de livros de primeiras leituras que atestam a importância da escola na constituição de uma memória estética e afetiva da nossa sociedade. Desde as cartilhas de ensino da leitura até os livros didáticos e a literatura, as pesquisas acerca do livro escolar afirmam que foi imprescindível a tarefa de disseminação da cultura letrada como separação entre civilização e barbárie. Também os estudos sobre as coleções editoriais advertem a respeito do papel que iniciativas como a Biblioteca Pedagógica Brasileira, da Companhia Editora Nacional, e a Bibliotheca de Educação, da Companhia Melhoramentos, tiveram na configuração da educação como campo de atuação profissional e especializada (CARVALHO; TOLEDO, 2007). Noutro âmbito, as próprias bibliotecas escolares eram locais de configuração de acervos relevantes para a memória cultural de certos grupos sociais. Os trabalhos de Diana Vidal (2001), Maria Teresa Santos Cunha (2009) e Cássia Kirchner (2016) já mostram algo dos modos pelos quais a biblioteca escolar dispõe, ou não, aos leitores um acervo pacientemente administrado.

Para além das marcas de leitura, dos registros de controle e do inventário dos exemplares, cumpre ainda perguntar sobre as funções mnemônicas dessas práticas, dos catálogos de consulta e suas palavras-chave e índices de assunto. As remissões que atualmente os bancos de dados realizam online e que, anteriormente, eram realizadas por meio de fichas de autores e assunto, fazem das bibliotecas uma instituição da memória cultural porque dão acesso à memória virtual dos livros. Dessa perspectiva, as análises de Namer (1987) tratam das práticas cognitivas do trabalho intelectual, das operações de anotação, da cópia e de todos os demais fazeres que são exigidos no uso do livro numa biblioteca. Elas advertem acerca das numerosas mediações que separam o livro do leitor e apontam para a centralidade do trabalho do bibliotecário na atribuição das classificações, bem como do papel que cumprem na afirmação de uma memória cultural.

Os acervos de livros propriamente mantêm uma relação de determinação com a memória do lugar aos quais pertencem. $O$ trabalho com os acervos bibliográficos do Real Gabinete Português de Leitura, do Instituto de Educação do Rio de Janeiro 
e da Biblioteca Nacional, por exemplo, tem nos mostrado ser útil compreender as práticas de uso do livro que não são da ordem da leitura. Nesse sentido, os estudos da história de grandes bibliotecas de instituições públicas que ainda funcionam atualmente e de seus catálogos permitem entender o livro enquanto artefato cultural e a biblioteca como lugar de significação das práticas de organização e uso do acervo. A compreensão dos modos de composição dos acervos ao longo do tempo passa, assim, pelo problema da ordenação cronológica de qualquer outro conjunto de artefatos. O uso de catálogos e processos de compra e aquisição dão acesso a importantes pistas dos estratos que conjuntos inteiros de livros ocupam na história de uma biblioteca. Como na arqueologia, pode-se pensar, para uma biblioteca, o estabelecimento de uma cronologia de composição dos acervos por meio de um modelo distributivo de identificação e questionar-se sobre os tipos de investimentos de aquisição dos livros realizados por períodos. A história dos começos da Biblioteca Nacional e do Real Gabinete Português de Leitura, ou da organização da Biblioteca de Professores do Instituto de Educação, reúne análises que permitem pensar a tradição que conferiram ao Império ou à formação de professores.

Além do sistema de referenciação e classificação e, assim, das questões de acesso ao acervo, há os seus modos de constituição. Trata-se da alocação do acervo, da composição das coleções e dos arranjos que conferem estabilidade e solidez às bibliotecas. Portanto, dos itinerários que os livros, reunidos, conjugados e classificados, ostentam e possibilitam como significado e sentido pode-se depreender alguma intenção. Lilian Schwarcz (2002, p. 418), por exemplo, percebeu na maneira como a Real Biblioteca seria guardada na memória um significado e um sentido: era a Independência que se fazia tradição, os livros do seu acervo carregavam os sinais de independência cultural e intelectual.

Trata-se de um lugar de memória diferente daquele que se dá com a ruptura da relação entre a significação cultural e os contextos sociais que definem o significado de um objeto no museu ou um manuscrito no arquivo. Assim, a biblioteca aparece como um lugar de memória de natureza diferente do museu ou do arquivo. Ela não se ampara na espécie de drenagem do valor original de um objeto no museu, nem na conservação do valor de prova de uma documentação de arquivo, mas, como sugere Namer (1987, p. 168), na grande necessidade social de atualização da memória cultural. Mais que a raridade, $\mathrm{o}$ arranjo ou a proveniência, seu acervo é distinguido pelo modo como hierarquiza, por meio dos catálogos e fichas, as formas de acesso aos livros. A biblioteca é, então, para Namer (1987, p. 169), uma instituição de memória, na medida 
em que a sociedade possibilita criar condições de acúmulo e manutenção de livros, e também na medida em que se considera que uma certa prática de memória, científica e cultural, é indispensável para uma parte da sociedade. Essa dimensão social da memória que a biblioteca administra e organiza sofre as injunções de poderes diversos. As aquisições dos livros do acervo e o desenvolvimento de coleções variam conforme o gosto do patrocinador, as pressões políticas dos editores, dos autores ou das autoridades públicas, as indicações de especialistas de todas as áreas do saber e o reconhecido sucesso popular de alguma publicação (KENSKI, 2001, p. 74).

De fato, as condições de produção e circulação do livro também são parte da história de composição dos acervos das bibliotecas. A aquisição de obras nutre o ciclo de vida do livro, que, conforme explica Darnton (1990, p. 112), é "um circuito de comunicação que vai do autor ao editor, ao impressor, ao distribuidor, ao vendedor e chega ao leitor". Entre a compra e a leitura, a biblioteca incorpora o livro a um acervo que lhe ressignifica as condições de uso e, sobretudo, referencia-o a um dado sistema de classificação do saber.

Assim, a história da composição do acervo, seu sistema de referenciação, as condições de produção e circulação do livro e as relações que leitores, autores, editores, impressores, livreiros, professores, distribuidores e intelectuais mantêm entre si e com o saber e a cultura fazem da biblioteca um espaço muito particular de criação e sociabilidade da memória. Nesse sentido, pareceu-nos que depois de sugerir, apoiados nas considerações de Gerard Namer, que o livro na biblioteca é um artefato de memória, pensar esse espaço de acumulação como um lugar de interação de inúmeras memórias culturais e colocar a questão dos espaços de sociabilidade organizados em torno do livro permite explorar bons veios de trabalho e pesquisa. No que se segue, procuramos, então, chamar a atenção para as formas como historicamente as bibliotecas escolares têm viabilizado a relação entre a memória encerrada no livro fechado e a obrigação ou necessidade social que impele os leitores a demandar livros.

\section{A ESCOLA E os USOS Do LIVRo NA BIBLIOTECA: UMA MEMÓRIA DAS PRÁTICAS}

Central para o projeto de renovação escolar no Brasil, a criação de bibliotecas escolares e para professores foi parte das iniciativas de reforma do ensino entre as décadas de 1920 e 1930. Na capital federal e em São Paulo se sucederam as iniciativas para associar bibliotecas a escolas primárias nesse período. Bem mapeadas do ponto 
de vista da regulamentação, os dispositivos do Decreto 2.940, de 22 nov. 1928, que previam a instalação de bibliotecas e museus em cada escola primária, a organização da Biblioteca Central de Educação pelo decreto 3.763, de 1 fev. 1932, no Distrito Federal, a implantação da Biblioteca Pedagógica Central em 1931 e o Código de Educação de 1933 em São Paulo, que criou o Serviço de Bibliotecas e Museus Escolares e a Biblioteca Central de Educação do Departamento de Educação, foram os mais significativos.

Curiosamente assentada num discurso que se insurgia contra a escola livresca, a legislação que entre as décadas de 1920 e 1930, em São Paulo e Rio de Janeiro, modificou as condições de oferta dos serviços educativos, fomentou, especialmente, a criação de bibliotecas escolares. Assim, no Distrito Federal, em 1928, a regulamentação da lei 2.940, por meio do artigo no 629, determinava que "para despertar o interesse dos alunos pelos livros e para servir de complemento ao trabalho do mestre" deveria haver em cada escola pública uma biblioteca dividida em duas seções: uma para professores outra para alunos. Do mesmo modo, em São Paulo, o Código do Ensino de 1933 previa que, para a organização de bibliotecas escolares, os professores e diretores escolares podiam valer-se de contribuições diversas (art. 109). Responsável pela coordenação do trabalho das comissões de ambas as legislações, Fernando de Azevedo (1946, p. 115) tinha claro que "não se pode conceber uma cultura sem livros". Cumpria mesmo aos professores ensinar os homens a se servir do livro e, segundo entendia Azevedo (1946, p. 114), parte da autoridade docente dependia do manuseio do livro:

(...) se o mestre oculta aos estudantes a própria fonte dos seus conhecimentos; se longe de instigá-los tanto à investigação como ao comércio constante dos livros, se mostra indiferente a que os alunos leiam ou talvez mesmo hostil à sua curiosidade intelectual, e, escravizando-o às suas notas e às suas explicações, não os convida à discussão, à pesquisa e ao laboratório; se o seu ensino, que deveria ser espírito e chama, pelo impulso de sua vida interior, de uma vida rica e que se dá, se transforma em rotina e mecanismo; adeus, autoridade!

Essa concepção trazia as marcas dos embates contra um ensino puramente expositivo e dogmático, assentado sobre manuais, em favor de uma educação centrada em toda ordem de pesquisas, tanto em livros como em laboratórios. O próprio Azevedo (1946, p. 115) se ocupou do mal-entendido, denunciando que, "sob o pretexto de se condenar a cultura livresca, no sentido pejorativo da palavra, o que 
se pretendia afinal era consagrar, por indolência, o próprio princípio de que o bom senso e a prática podem bastar-se a si mesmos”. Ao contrário, entendia que não se deveria querer mal aos livros "pelo mal que nós próprios nos fazemos, por não sabermos aproveitá-los” (AZEVEDO, 1946, p. 116). Azevedo (1946, p. 109), especialmente, mostrou-se entusiasmado com a difusão extraordinária de bibliotecas, com seu aparato de instalações e de materiais e com o enriquecimento das suas coleções, sublinhando que "a ideia de levar os livros a todos ganhou terreno, desenvolvendo-se mais ou menos, de acordo com (...) a maior ou menor permeabilidade das culturas nacionais às correntes renovadoras da biblioteca e da educação".

É característica da legislação desse período cuidar dos modos de constituição do acervo. Em 1928, a lei de ensino determinava que a biblioteca escolar só poderia ser formada com exemplares de livros aprovados pelo Conselho de Educação e doados pelas autoridades ou particulares. Prescrevia ainda que nenhum livro doado seria incluído na biblioteca sem o exame do diretor da escola. Em São Paulo, segundo o Código de 1933 bastava, para organizar a biblioteca escolar, aos diretores e professores das escolas se valerem da contribuição das associações de pais e mestres, do auxílio da municipalidade, da doação de livrarias e casas editoras, de produtos das festividades. A leitura do Programa de Linguagem publicado no ano seguinte pelo Departamento de Educação do Distrito Federal mostra que também havia critérios de escolha específicos. Na sexta seção deste programa, intitulada "Biblioteca", encontra-se toda uma tipologia de gêneros considerados apropriados:

De modo geral podemos indicar duas categorias de livros: de informação ou didáticos, e de literatura. Como livros de informação ou didáticos classificaremos todos os que servem a ministrar noções, a auxiliar o trabalho de classe, a completar as observações dos alunos; nesse grupo ficam os livros de geografia, história, aritmética, álbuns diversos, revistas científicas etc., etc. Como livros de literatura os que servem: a) para despertar o gosto pela leitura (livros de estampas, álbuns, livros de histórias, folhetos diversos com figuras, etc); b) os que servem para aprendizagem e cultivo da leitura (livros de histórias, contos, seletas, romances, etc.) entrando nessa categoria as revistas e jornais (DISTRITO FEDERAL, 1962, p. 117-118).

Desse universo de livros, sabe-se o suficiente das suas principais características por meio do que a historiografia já reuniu acerca da literatura escolar. Agradáveis e interessantes, deviam atentar para aspectos da formação moral sem preocupação 
ostensiva de pregar moral e, principalmente, possuir forma literária de acordo com a mentalidade das crianças a que se destinavam. Estudos sobre Contos Infantis (VIDAL, 2005) ou Através do Brasil (SANTOS, 2015) prestaram especial atenção aos artifícios de adequação da escrita literária ao público escolar. Mais abrangentes, o panorama da literatura infanto-juvenil de Nelly Novaes Coelho (2010), ou as análises de Patrícia Hansen (2007) acerca da literatura infantil do início do século passado e de Cássia Kirchner (2016) sobre a coleção Biblioteca das Moças reiteram as qualidades centrais da literatura que vai para a escola: simplicidade, precisão e correção da linguagem e um certo calor e entusiasmo para dar graça e vigor à narrativa.

De outro gênero, os livros didáticos, que servem para ministrar noções, auxiliar o trabalho de classe e completar as observações dos alunos, reúnem análises de todas as áreas do currículo. Os estudos sobre as cartilhas utilizadas para a alfabetização, os manuais de história, matemática, ciências ou geografia e mesmo guias de ensino ou higiene, sugerem haver todo um repertório de títulos e gêneros voltados para a escola, o qual varia no período entre fins do século XIX e fins do século passado em três grupos distintos. Inicialmente, entre 1880 e 1920, um período de predominância de obras de caráter enciclopédico, conforme mostram os estudos que se detêm nos livros com circulação nos Liceus e escolas normais (SOARES, 2017). Depois, segue-se um intervalo de tempo com a vigência de séries didáticas e de leitura infantil e obras adaptadas, entre 1920 e 1950, em boa parte vinculada ao movimento de renovação educativa dos anos 1920 e 1930. As análises de Toledo (2001), especialmente, atestam esse movimento no mercado editorial do período, também percebido por Rafaela Rabelo (2016) nas coleções das bibliotecas da antiga Faculdade de Ciências e Letras da USP, do Centro Regional de Pesquisas Educacionais de São Paulo e da coleção Paulo Bourroul, da antiga escola normal da capital. Finalmente, um período entre 1950 e 1980, que pareceu transformar a biblioteca escolar num importante repositório mercantil de certas casas editorias e de coleções subvencionadas pelo poder público. A série de coleções editadas por grandes selos, Saraiva, Cia Editora Nacional, José Olympio, por exemplo, apontam para uma destinação escolar, como parece indicar a pesquisa de Cássia Kirchner (2016) acerca dos exemplares da Biblioteca das Moças na biblioteca do Instituto de Educação Carlos Gomes.

O conjunto de livros frequentado por quem estuda a história da educação sugere ainda que, além das transformações ao longo do tempo, há outras características úteis à compreensão dos esquemas de composição de coleções voltadas à escola. Em primeiro lugar, a diferença que as pesquisas do livro e da leitura marcam entre os títulos 
em circulação nas escolas primárias e secundárias é significativa, como mostram as comparações entre estudos sobre os Liceus e as práticas de leitura na escola primária. Depois, a consolidação de gêneros próprios e estritamente adequados às atividades escolares, conforme lembra Chartier (2007, p. 70), anima um trabalho editorial específico de modo a atender um mercado. Do mesmo modo, e ainda segundo Chartier (2007), os autores querem responder a uma demanda já reconhecida, ao passo que creem responder a uma expectativa ainda não satisfeita (CHARTIER, 2007, p. 70). Além dos manuais didáticos, a literatura infantil e as coleções editoriais também se constituíram em veículos de políticas culturais e educacionais. Atualmente, programas como o Programa Nacional do Livro Didático e o Programa Nacional Biblioteca da Escola se reconhecem nessa mesma tradição de fomento da leitura por meio da escola.

Enfim, os vestígios a respeito da alocação dos acervos, da sua composição e arranjo dão lugar a estudos sobre o projeto político que os havia constituído. O modo como Diana Vidal (2001) mostra a maneira pela qual, nos anos 1930, a biblioteca da Escola de Professores do Instituto de Educação foi utilizada para aglutinar discursos de excelência e aprimoramento profissional confere significado e sentido para uma certa memória do período. Nas aquisições de então, Vidal (2001, p. 182) percebe a mudança de um perfil do acervo que se moderniza de acordo com os propósitos de formação do Instituto. Até aquele momento, avalia, "a biblioteca dispunha de grande número de obras editadas no século XIX”, passando a adquirir os volumes lançados no mercado editorial. Para os reformadores que conduziram esse processo, a Biblioteca era um trunfo, um meio de conferir longevidade às suas ideias - dava história e tradição para um movimento de renovação que vivia momentos decisivos.

Estudos como os de Vidal (2001), Rebelo (2016) e Kirchner (2016) advertem que sem conhecer os modos de alocação dos acervos das bibliotecas escolares e da composição das suas coleções a compreensão do projeto político que os animou em um determinado período fica prejudicada. De fato, como sugerem as análises de Namer (1987), o entesouramento de que o livro é passível numa biblioteca constitui e solidifica práticas de leitura, forma particular de memória cultural. Para retornar às reflexões deste autor, é também através de todo um sistema de referenciamento e classificação que as bibliotecas exercem uma função seletiva de memória. A organização das bibliotecas escolares dos anos 1930 deixaram boas evidências de que parte da sua função educativa era difundir as boas práticas da leitura e evitar o "mal que nós próprios nos fazemos", por não sabermos aproveitar os livros. 
As diferentes formas de facilitação ou não da manipulação das obras disponíveis numa biblioteca exercem um poder diante da memória cultural e intelectual escrita. Assim, o próprio fato de se organizar bibliotecas nas escolas já demonstra um compromisso com esse tipo de memória. Nos anos 1930, tanto os guias e a legislação de ensino quanto os princípios bibliográficos de organização do saber apontam para o quanto essa memória resultava de uma rígida disciplina de trabalho. Diretor da Biblioteca Central Pedagógica criada por Lourenço Filho em 1931, Achilles Raspantini (1932, p. 55) preocupou-se em testemunhar sobre o desafio de catalogar livros de grandes bibliotecas do ponto de vista da biblioteconomia. Dizia:

Consideramos uma biblioteca, não como um simples repositório de livros, mas como um instrumento de pesquisas; e reconhecemos que esse instrumento tem de ser prático e completo. Sabemos também que há na catalogação, como em tudo o mais, uma técnica especial, que exige um aprendizado, uma longa prática e uma consideração extrema das minúcias.

No duplo objetivo dos catálogos de dizer quais são os livros da biblioteca e de indicar onde se acham, Achilles Raspantini (1932, p. 55) distingue quatro tipos: onomástico, didascálico, de assunto e topográfico. Adverte, ainda, que há uma importante diferença entre catálogo e classificação. Enquanto a classificação apresenta os conceitos de um modo ideológico, o catálogo os ordena alfabeticamente. Uma prática implica a existência da outra e, ao menos assim parecia a Raspantini, o catálogo será tanto melhor quanto mais se aproximar de uma classificação que, em última instância, deveria ser simples e útil. Na distinção que então fazia entre classificação e catalogação, Raspantini reconhece as implicações de solidariedade, objetividade e utilidade que dão razão às reflexões de Namer (1987) quando este afirma:

... o catálogo sistemático, memória das memórias, joga o papel de quadro social da memória, tal como define Halbwachs: uma nova memória se adapta às categorias velhas (o livro encontra sua classe) ou as categorias se modificam (pela subdivisão da classificação; ou pela abertura de um novo segmento). Todavia o paralelismo com os "Quadros sociais" [da memória] tem seus limites: o título de um livro não é uma categoria para a sua classificação e a categoria não é um livro (apud. KENSKI, 2001, p. 74). 
Já no Programa de Linguagem, publicado em 1934 pelo Departamento de Educação do Distrito Federal sob a batuta de Maria Reis Campos, outras injunções aparecem. Especialmente, na preocupação que revelava com a organização de uma biblioteca escolar e a forma de utilizar os livros em um espaço desse tipo se observa todo um outro domínio de práticas. Por um lado, então, as recomendações de uso dos livros que não são da ordem da leitura e, por outro, as recomendações em torno da leitura na escola. Do primeiro tipo de recomendações, as orientações insistem que a biblioteca deveria oferecer aos alunos noções práticas de ordem e, assim, um "ambiente agradável, de ordem sem robustez, de alegria sem ruído, de atividade sem balbúrdia, ambiente disciplinador e educativo por excelência” (BRASIL, 1962, p. 116). Já a manipulação do livro tinha prescrições particulares aos alunos:

a. lidar com os livros, com a preocupação de poupá-los e conservá-los (mãos limpas, abrir o livro sem forçar a encadernação, voltar as páginas sem amassá-las ou rasgá-las);

b. utilizar-se do catálogo e saber encontrar os livros de que necessitem;

c. utilizar-se dos índices, sumários e outras indicações para encontrar a informação de que estão precisando (BRASIL, 1962, p. 116).

Quanto às recomendações acerca da leitura na escola, previa-se dois tipos, a saber: com ou sem assistência do professor. Sem o auxílio do professor, os livros indicados eram os de literatura, pois tinham a finalidade de despertar o gosto pela leitura. Nesse caso, os livros didáticos eram indicados como fonte de informação, em trabalho que pudesse ser feito pelo aluno. Depois, a utilização na sala de aula era indicada para os casos em que havia intervenção ou assistência do professor ou, mesmo, uma ação coletiva dos alunos. Nesse outro caso, "os livros vêm então à classe para servir às lições de momento, para exemplificações e citações que o professor queira fazer, para leitura coletiva" (BRASIL, 1962, p. 114-115).

O Programa de Linguagem sobrepõe aos instrumentos de classificação e catalogação do bibliotecário as práticas de leitura e os usos do livro selecionados pela tradição escolar da disciplina, da ordem, da colaboração e do gosto e utilidade. Nesse sentido, ao menos na escola dos anos 1930, a biblioteca serviu ao propósito de formar leitores segundo um modelo de escolarização que fazia da leitura um elemento não só da formação intelectual, mas da formação moral da criança. Sobretudo, a biblioteca era um lugar de ordem, de calma, de recolhimento e beleza, 
prescrita na escola como "santuário onde o espírito repousa, entre emoções estéticas de suavidade" (BRASIL, 1962, p. 115). A chamada influência do ambiente e o conjunto de práticas em torno do lugar de leitura na escola devia ensinar tanto quanto o acervo de livros.

\section{Nota FINAL}

Na escola dos anos 1930, a biblioteca reunia um repertório de práticas, voltadas para o livro, que não eram só da ordem da leitura e que se incumbiam de propiciar aos alunos noções práticas de utilização. $\mathrm{O}$ ensino da boa maneira de tratar o livro, do modo de se utilizar dele para se obter as informações desejadas ou do hábito do silêncio e do recolhimento associava à leitura, ao livro e ao leitor um universo de representações significativas. Por um lado, a classificação e a catalogação, e o sistema de conhecimentos que as bibliotecas recriavam, não só exigiam orientação de uso como, principalmente na percepção de Namer (1987), evocavam uma certa organização escolar dos saberes. Por outro, era previsto todo um conjunto de instrumentos educativos particularizados para assegurar uma correta iniciação ao "sentido misterioso dos sinais gráficos" (BRASIL, 1962, p. 115). A ordem, a disciplina, o silêncio, a colaboração e a eficiência que envolviam as atividades intelectuais de então compunham um conjunto de procedimentos capaz de reafirmar na escola o valor social do livro como artefato de cultura.

Nesse sentido, tanto quanto a composição, a classificação e catalogação do acervo, os usos que se organizam em torno do livro numa biblioteca testemunham algo da expectativa cultural construída pela escola acerca das práticas de leitura e das boas formas de se aproveitar os livros.

\section{REFERÊNCIAS}

AZEVEDO, F. Seguindo meu caminho. São Paulo: Companhia Editora Nacional, 1946.

BITTENCOURT, C. Livro didático e saber escolar (1810-1910). Belo Horizonte: Autêntica, 2008.

BRASIL. Linguagem na escola primária. Brasília: MEC, 1962.

CARVALHO, M.; TOLEDO, M. R. Os sentidos da forma: análise material das coleções de Lourenço

Filho e Fernando de Azevedo. In: OLIVEIRA, M. A. T. (Org.). Cinco estudos em História e Historiografia da educação. Belo Horizonte: Autêntica, 2007, p. 89-110.

CHARTIER, A-M. Práticas de leitura e escrita: história e atualidade. Belo Horizonte: Autêntica, 2007. COELHO, N. N. Panorama histórico da literatura infantil/juvenil. São Paulo: Amarylis, 2010. 
CUNHA, M. T. S. (Org.). Uma biblioteca anotada: caminhos do leitor no acervo de livros escolares do Museu da Escola Catarinense. Florianópolis: UDESC, 2009.

DARNTON, R. O beijo de Lamourette: mídia, cultura e revolução. São Paulo: Companhia das Letras, 1990. HANSEN, P. Brasil, um país novo: literatura cívico-pedagógica e a construção de um ideal de infância brasileira na primeira república. 2007. Tese (Doutorado em História Social) - FFLCH-USP, São Paulo, 2007.

KENSKI, V. As instituições culturais de memória na era da multiplicidade eletrônica. Educação e Linguagem, ano 4, n. 4, p. 67-97, jan./dez. 2001.

KIRCHNER, C. Rastreando práticas de leitura. Um estudo indiciário sobre possíveis leitoras da Coleção Biblioteca das Moças na Biblioteca do Instituto de Educação Carlos Gomes em Campinas. Tese (Doutorado em Educação), FE/Unicamp, 2016.

NAMER, G. Mémoire et société. Paris: Méridiens Klincksieck, 1987.

RABELO, R. Destinos etrajetos: Edward Lee Thorndike e John Dewey na formação matemática do professor primário no Brasil (1920-1960). Tese (Doutorado em Educação). FEUSP, São Paulo, 2016. 286p.

RASPANTINI, A. Biblioteconomia. Educação, vol. X, p. 54-8o, out-nov. 1932.

SANTOS, C. Através do Brasil, uma trajetória centenária. São Cristovão-SE: Editora UFS, 2015.

SCHWARCZ, L. A longa viagem da Biblioteca dos Reis. São Paulo: Cia das Letras, 2002.

SOARES, W. Uma história da matemática escolar na cidade de São Luís do século XIX: livros, autores e instituições. Tese (Doutorado em Ensino de Ciências e Matemática) - FE/UNICAMP, Campinas, 2017.

TOLEDO, M. R. A. Coleção Atualidades pedagógicas: do projeto político ao projeto editorial (19311981). Tese (Doutorado em Educação). PUC-SP, São Paulo, 2001. 295p.

VIDAL, D. Culturas escolares. Campinas: Autores Associados, 2005.

VIDAL, D. O exercício disciplinado do olhar. Bragança Paulista: EDUSF, 2001.

\section{SOBRE O AUTOR}

André Luiz Paulilo é graduado em História (Universidade de São Paulo) e tem Mestrado e Doutorado em Educação (Universidade de São Paulo). É professor no Departamento de Filosofia e História da Educação da Universidade Estadual de Campinas e diretor do Centro de Memória-Unicamp. Tem experiência na área da educação, com pesquisa nos seguintes temas: história da educação, cultura escolar contemporânea e patrimônio educativo. É bolsista CNPq. E-mail: paulilo@unicamp.br.

Recebido em o1 de março de 2019 e aprovado em 10 de junho de 2019. 